\title{
Application of Genetic Algorithm Methods for Water Turbine Blade Shape Opti- mization
}

\author{
Martin Kantor ${ }^{1}$, Milan Chalupa ${ }^{1}$, Jiří Souček ${ }^{2}$, Eva Bílková2 ${ }^{2}$ Petr Nowak ${ }^{2}$ \\ ${ }^{1}$ Faculty of Mechanical Engineering, J. E. Purkyně University, Adress: Na Okraji 1001/7, Ústí nad Labem 40001 \\ Czech Republic, E-mail: martin.kantor@ujep.cz, milan.chalupa@ujep.cz \\ ${ }^{2}$ Faculty of Civil Engineering, Czech Technical University in Prague, Adress: Thákurova 7, Praha 16629 Czech \\ Republic, E-mail: jiri.soucek.2@fsv.cvut.cz, ebilkova@post.cz, petr@nowak.cz
}

The use of modern production techniques such as 3D printing brings new requirements for shaping machine parts. In the case of the production of the runner blades of Kaplan micro-turbine using 3D printing technology from plastic, the emphasis is on the mechanical properties of the blade and hydraulic properties of the entire turbine. Achieving the required parameters is conditioned by finding a suitable shape of the runner. Therefore the design, virtual testing, optimization and evaluation process is automated. The paper describes the whole process where virtual testing of hydraulic parameters is performed by CFD simulations, and the methods of genetic algorithms are used for optimization. Selected final geometrical shapes of the blade are subjected to a more detailed analysis of hydraulic parameters in the wider operating range and also to the strength analysis.

Keywords: low head Kaplan turbine, Optimization, CFD simulations, FEA simulations, 3D printing

\section{Introduction}

The demand to increase the production of electricity from renewable sources points to the possibility of exploiting the potential of existing locations whose hydropotential is not yet fully exploited. The use of these sites is conditioned by the use of cost-effective solutions with appropriate operational features and minimum construction interventions. The required solution is achieved by using modern technologies for the production of water turbines, such as $3 \mathrm{D}$ printing of parts, minimization of mechanical parts and use of frequency converters to control the turbine speed and its discharge (see Fig. 1). All these requirements lead to a complex new design of the hydraulic part of the turbine.
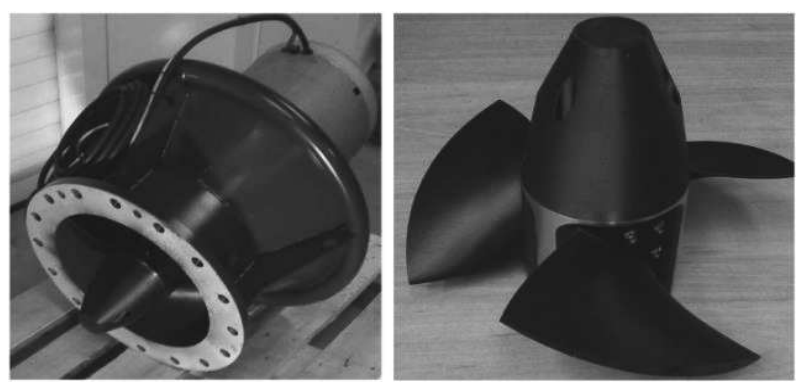

Fig. 1 The prototype from the previous solution, on the left the compact turbine, on the right - the runner from the components made by $3 D$ printing

\section{Solution description}

The process of the whole design and virtual testing, optimization and evaluation are controlled (via SW connection) from the CAESES environment (see Fig. 2). The geometrical model of the whole turbine is fully parametric and is created in the software CAESES. [1] The hydraulic properties of the turbine are evaluated based on flow simulation in SW ANSYS CFX using structured meshes created in SW ANSYS TurboGRID. [2] Sensitivity analysis of control parameters reveals the effects of individual parameters on the required hydraulic properties of the turbine. Further, the shape of the runner blade is optimized to increase hydraulic efficiency and improve cavitation properties for a defined operating point. A multi-objective genetic algorithm (MOGA) contained in the Dakota SW CAESES module [3] is chosen for optimization. Based on the evaluation of hydraulic properties, the most suitable shape is chosen for further testing and utilization.

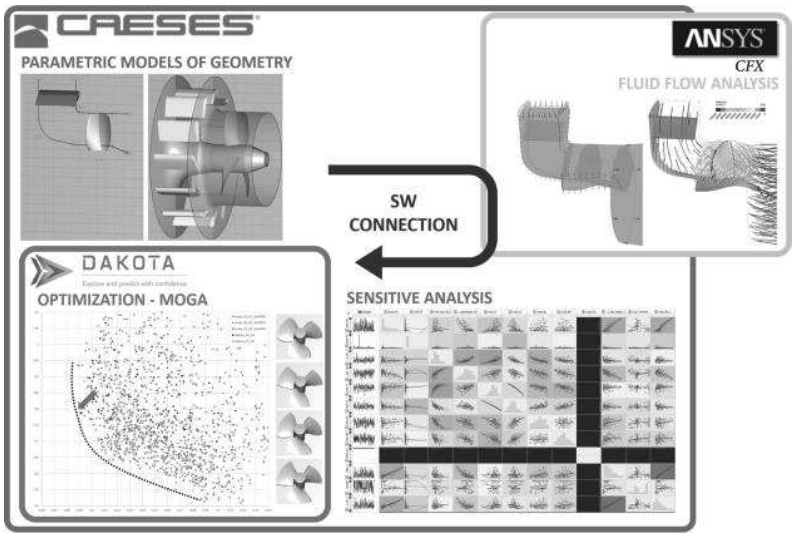

Fig. 2 Workflow - Design and evaluation process diagram 


\section{A parametric model of turbine geometry}

The geometric model of the whole turbine is created in the CAESES environment and is fully parametric. The shape of the hydraulic profile consists of control points and curves (see Fig. 3). The guide blade is prismatic along with its height and is defined by a single control section, which is formed by a curve controlled by several points (see Fig. 3). The process of forming a runner blade is described in [4][5]. The blade is formed by rolling the thickness on the camber mean-line and transforming its shape into cylindrical cuts defining the blade surface.

The blade is defined by distributing the following parameters over its width: blade inlet and outlet angle, profile length, maximum blade thickness, maximum camber position, maximum blade camber ratio, the radius of the inlet edge (nose circle) of profile and the position of the blade rotation points ( 2 parameters). After simplifying and linking some parameters, the shape of the runner is controlled by a total of 24 parameters (see Table 1). Other parameters control the global rotation of the guide blades and runner blades around their axis ( 2 parameters) and the number of individual blades in the turbine ( 2 parameters) - see Tab. 1. There are limits for individual control parameters within which the value can change during the process of sensitivity analysis or subsequent optimization.

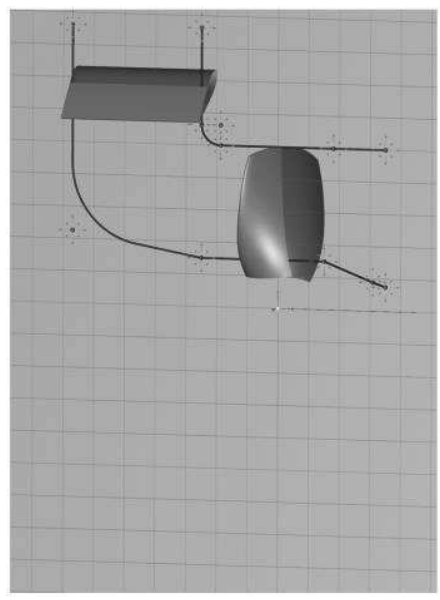

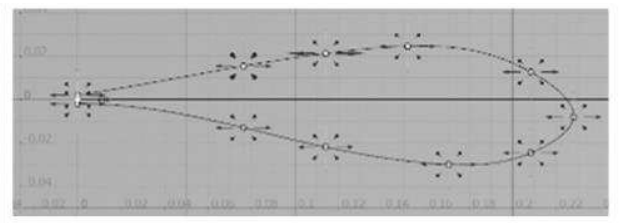

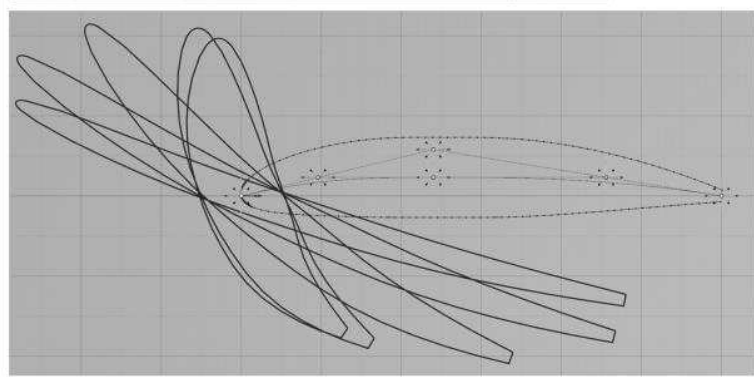

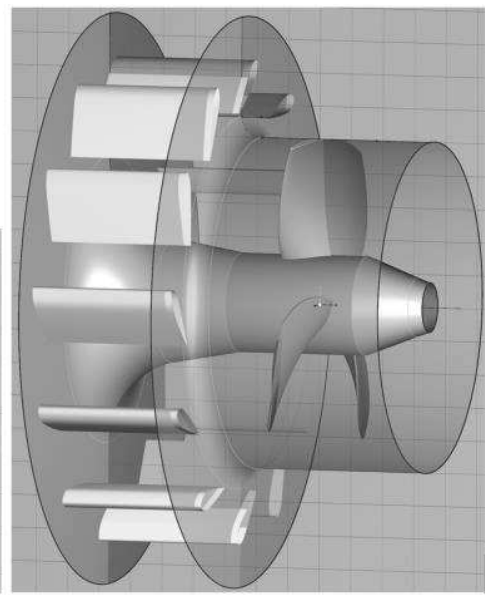

Fig. 3 A parametric model of geometry, on the left - bydraulic profile, on the middle - blades, on the right-full geometric model of turbine

\section{Flow simulation}

The process of virtual verification of hydraulic parameters by numerical flow simulation (CFD) is described in detail in the articles [6][7]. The whole process of CFD assessment is performed in the ANSYS

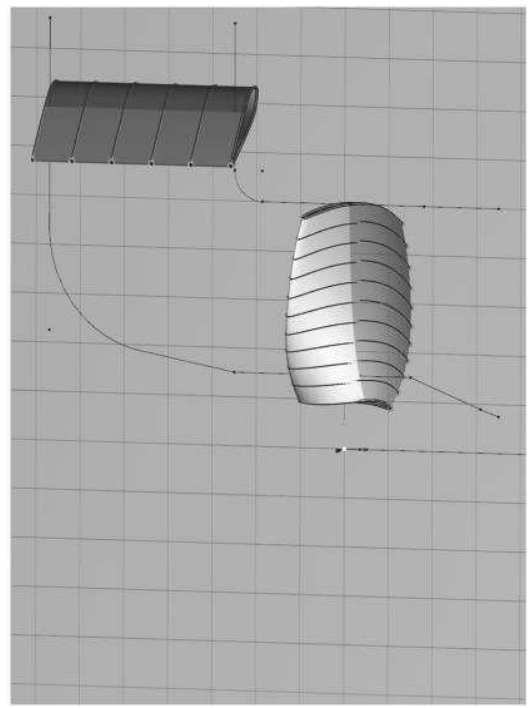

CFX environment. It is automated, and for a fast calculation, a stationary calculation is used on the whole turbine model (guide vane, runner blade, draft tube) using periodic segments for individual blade parts. The mesh of the model is structured and is created in the ANSYS TurboGRID environment.

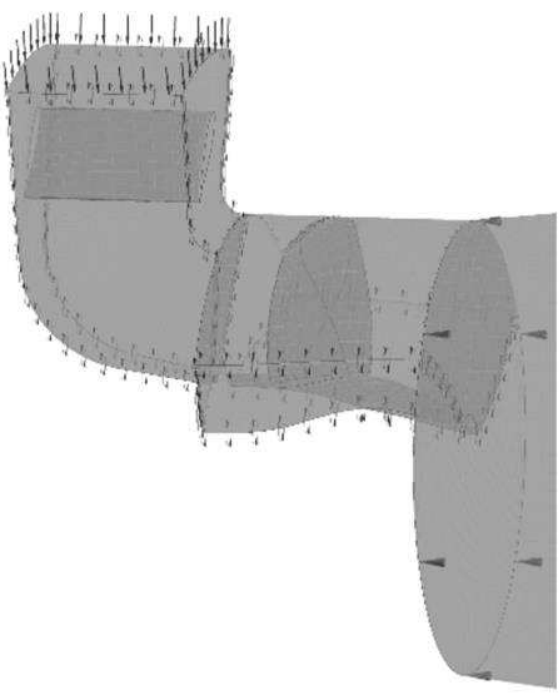

Fig. 4 Parametric model of geometry, on the right-control curves for computation mesh creation, on the middle - the model of CFD simulation, on the left - CFD simulation evaluation 
The total time of virtual assessment of hydraulic parameters of one particular design from the creation of the mesh to the actual simulation and evaluation takes in the order of 2-4 minutes. This time corresponds to the use of 4 computer cores per simulation and a mesh composed of 130,000 computational elements. The process of evaluating hydraulic parameters consists of evaluating: turbine flow rate $\left(\mathrm{Q}\left[\mathrm{m}^{3} \cdot \mathrm{s}^{-1}\right]\right)$, overall turbine hydraulic efficiency and cavitation properties. The overall hydraulic efficiency of the turbine (eta, $\mathrm{t}[-]$ ) is evaluated based on the difference in total pressures at the turbine inlet and outlet cross-sections and the moment at the turbine shaft. [8] Cavitation properties for a high degree of automation are evaluated based on the static pressure distribution over the runner blade.[8] This pressure is related to the calculation head, and the sigma value (sigma, ref [-]) is calculated to the reference flow rate $\left(\mathrm{Q}, \operatorname{ref}\left[\mathrm{m}^{3} \cdot \mathrm{s}^{-1}\right]\right)$. [9] The target functions are expressed from these values, which are minimized during sensitivity analysis and optimization.

The first target function evaluated is the value for overall hydraulic efficiency:

$$
\mathrm{F} 1=1 \text {-eta, } \mathrm{t}[-],
$$

Where: eta,t...total hydraulic efficiency of turbine [-].

The second target function is the value for cavitation properties:

$$
\text { F2= sigma,ref [-], }
$$

Where: sigma,ref... sigma cavitation coefficient for reference flow Q,ref [-].

The process of sensitivity analysis and subsequent optimization is based on finding a minimum of target functions.

\section{Sensitivity analysis}

The sensitivity analysis of parameters determines the effects of individual parameters on the required hydraulic properties. For sensitivity analysis is chosen algorithm SOBOL included in SW CAESES.

In the first step of sensitivity analysis are fixed: the hydraulic shape of the turbine and shape of guide blade, partial parameters of shape of runner blade (see Tab. 1). The parameters analyzed include 16 parameters describing the shape of the runner blade and one parameter controlling the rotation of the guide blade about

its

axis (see Tab. 1). The total number of 17 control parameters corresponds to sensitivity analysis with a total of approx. 300 simulations so that correlations and correlations can be found.

The sensitivity analysis was found:

- the strongest link was found between the guide blade rotation parameter and the turbine hydraulic parameters;
- very important for achieving hydraulic parameters is the setting of parameters of the input and output angle of the blade, significant dependence was not found, the influence of the input parameters is individual;

- the influence of the blade profile length on the turbine speed was confirmed.

\section{Optimization}

Furthermore, the blade shape optimization is used to increase hydraulic efficiency and improve cavitation properties for a defined operating point with a design speed of $\mathrm{n}_{11}=175 \mathrm{rpm}$ and a three-blade runner. The MOGA (Multi-objective Genetic Algorithms) algorithm contained in the Dakota SW CAESES module was chosen for the optimization [10].

Based on the sensitivity analysis and previous experience concerning achieving the required parameters (high specific speed $\mathrm{x}$ discharge $\mathrm{x}$ structural vane strength), all parameters are fixed (see Tab. 1) except these

(see Tab. 1): rotation angle of the guide vane, inlet angle (describing the distribution of this angle over the blade width) and the exit angle ( $x 4)$ of the blade. A total of 9 free control parameters are selected for optimization.

The actual MOGA algorithm is based on a multiobjective genetic algorithm. Multi-objective means that the target functions that it minimizes are more than one, in our case two (hydraulic efficiency - F1 and cavitation - F2). Achieving a global minimum for both target functions at the same time is excluded from this task. It is true that if high hydraulic efficiency is achieved, cavitation will be worse, and vice versa. The aim is to find the optimal ratio of the two target functions - Pareto front. Within the optimization process, three samples are selected within one iteration cycle. For the total number of 700 simulation points, approx. 230 iteration cycles are selected.

The starting point of the design process is a state that has respected the past experience and has been manually optimized, indicated as INITIALIZATION in Graph 1. Initial hydraulic efficiency (eta, t) was already high about $90 \%$. Cavitation properties expressed as sigma, ref $=1.25$. Already by the sensitivity analysis process, similar hydraulic efficiency was achieved with a sharp improvement of cavitation properties to sigma, ref $=0.83$. The optimization process further increased the hydraulic efficiency to eta, $\mathrm{t}=90.7 \%$ when reaching the sigma cavitation coefficient, ref $=$ 0.77 . The whole process is graphically documented in Graph 1, where the individual combinations of the target functions F1, F2, and the envelope curve of the best Pareto - front solutions (curves) are evident. It is 
apparent from the outputs that the proposed algorithm is functional, the optimization process only slightly increases the achieved hydraulic efficiency, and the great benefit is achieved in the area of improving cavitation properties.

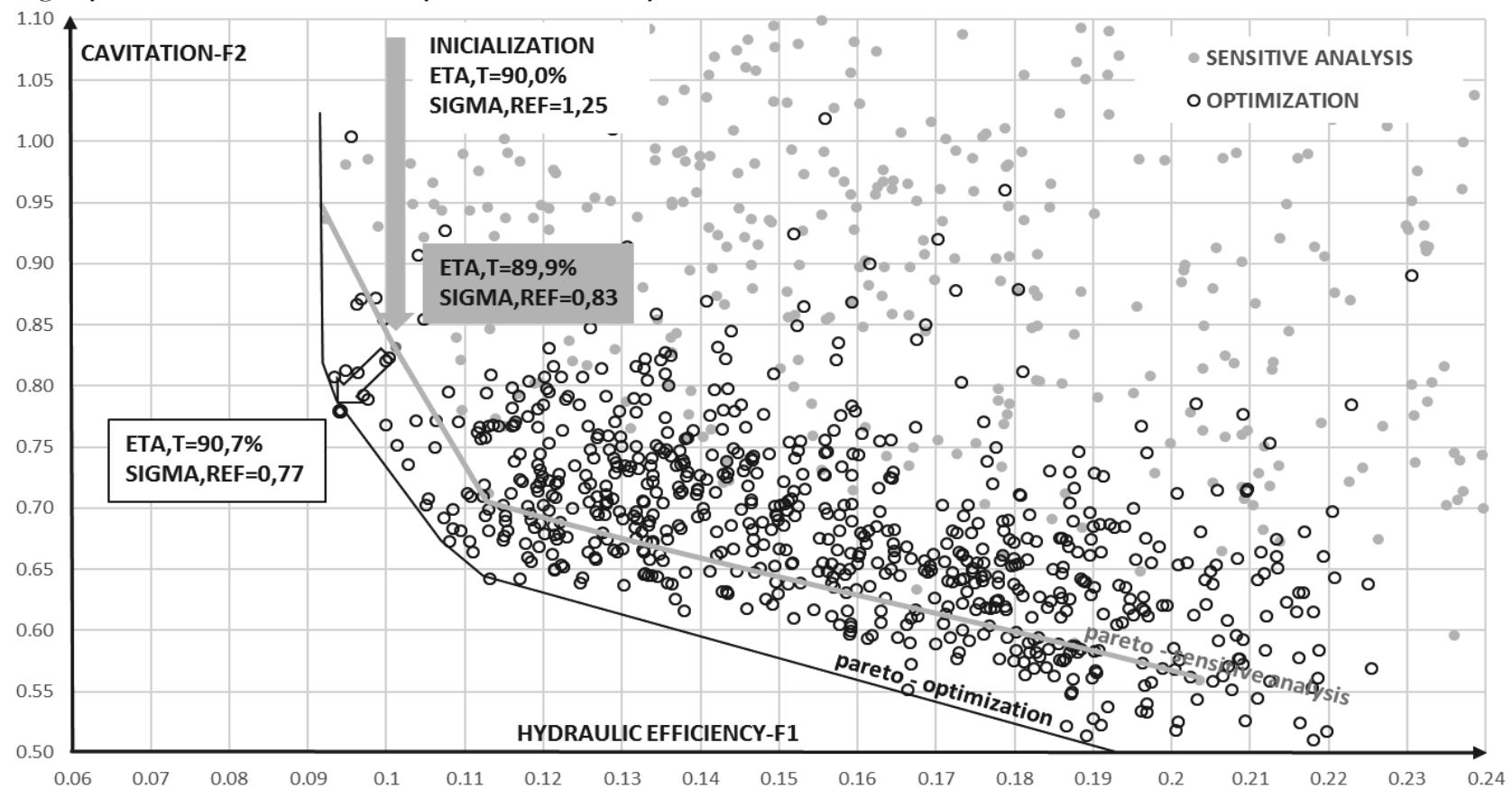

Graph 1 Simulation points in the area of the target functions F1 and F2

\section{Verification of hydraulic properties in a wider operating area}

Selected geometry (design with hydraulic efficiency eta, $\mathrm{t}=90.7 \%$ and cavitation coefficient sigma, ref $=$ 0.77 ) from the optimization process is subjected to parameter analysis for a wider operating area. This analysis is performed by flow simulation for different combinations of rotating vanes and runner blades and different unit speeds (unit speed $\mathrm{n}_{11}$ ) so that an ideal coupling is sought while achieving the highest hydraulic efficiency of the turbine.

From the analysis of the hydraulic properties of the selected geometry in the wider operating area, it is

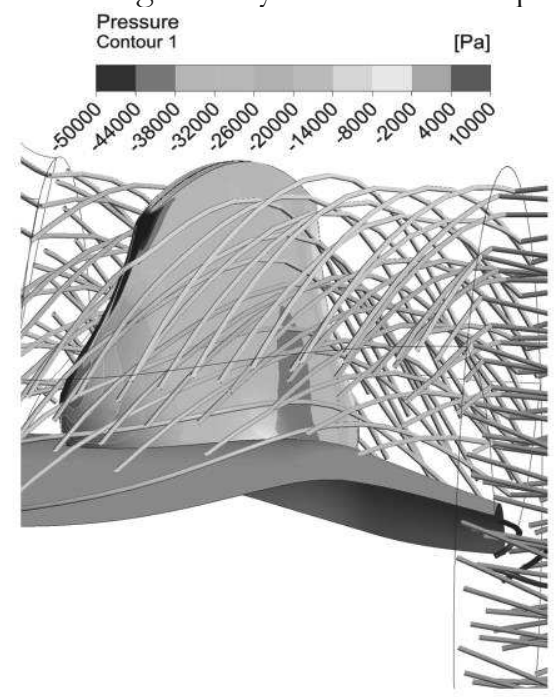

found out: the actual optimum of the turbine operation is at lower speed with the maximum achieved hydraulic efficiency eta, $\mathrm{t}=91.1 \%$ (design optimum $\mathrm{n}_{11}=175 \mathrm{~min}^{-1}$, real optimum $\left.\mathrm{n}_{11}=160 \mathrm{~min}^{-1}\right)$. The analysis shows high hydraulic efficiency (eta, t over $85 \%$ ) for a wide operating area.

\section{Strength analysis}

The subject is an assessment of stress-strain analysis of the turbine runner blade and its binding to the hub for selected operating conditions and technology of the production of the blades by $3 \mathrm{D}$ printing from plastic materials..

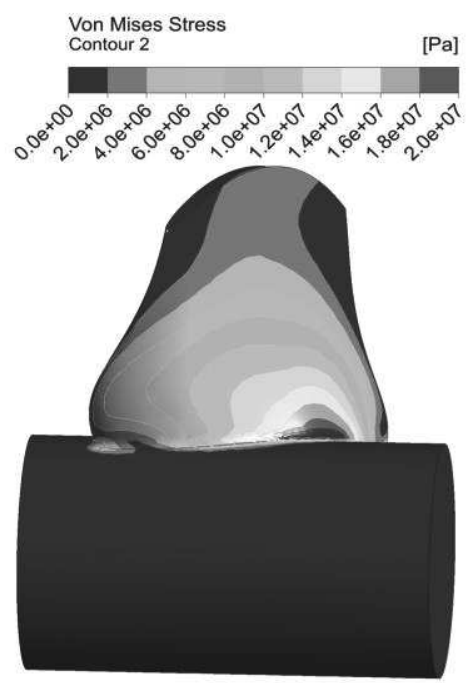

Fig. $5 \mathrm{~W}$ orkflow of the structural analysis, on the left - static pressure distribution from CFD, in the middle - settings and geometry of the structural analysis, on the right-distribution of the Von Mises Stress 
Analyses were performed with the following settings:

- Stress-strain analysis for a unit runner (in the following solution, the size of the runner will be changed to the appropriate size of the runner for a specific location);

- The runner blade load is taken from the flow analysis, i.e. the static pressure distribution for the individual operating points is imported;

- The geometric model contains the runner blade itself and its binding to the hub (see Fig. 5);

- The calculation is made for the material characteristics of structural steel $(\mathrm{E}=200 \mathrm{GPa}, \nu$ $\left.=0.3, \varrho=7850 \mathrm{~kg} \cdot \mathrm{m}^{-3}\right)$;

- The calculation for operating parameters (runner diameter $\mathrm{D}=1 \mathrm{~m}$, head $\mathrm{H}=4 \mathrm{~m}$, discharge, and power according to operating condition) and several operating points (max. power, max. efficiency, and runaway speed).

The calculations show:

- maximum von Mises stress is achieved in the point of connection of the runner to the turbine hub - see Figure 5;

maximum von Mises stress is reached for the maximum power output of the turbine unit

\section{Conclusion and evaluation}

This paper describes the process of designing and assessing a completely new Kaplan turbine hydraulic profile for specific applications. The design process also includes an algorithm for optimizing the shape of the runner blade in order to increase the utility properties of the water turbine. The whole workflow is fully automated and in the first tests the functionality has been proven, where the process of optimization for the given operating point increases both the hydraulic efficiency of the turbine and significantly improves its cavitation properties.

Overall, approx. 1200 flow simulations (see Table 1) with a total of 30 hours of machine time using 12core parallel run.

The most demanding steps of the whole process include: creating a fully parametric geometric model with interconnection and control of geometric input parameters; Creation of a fully automatic process of verification of hydraulic parameters using the flow simulation (CFD) method.

As part of the strength analysis [11], the material characteristics for the plastic material created by $3 \mathrm{D}$ printing will be introduced into the calculation, and the calculation will point out the possibilities of the technology used for the given application, possible limitations and necessary design changes (possible increase of blade thickness, blade reinforcement, etc.).

Tab. 1 Definition of individual parameters for a different design and evaluation levels

\begin{tabular}{|c|c|c|c|c|c|c|}
\hline Part & Parameters & $\begin{array}{l}\text { Num. } \\
\text { of param. }\end{array}$ & $\begin{array}{l}\text { Geometry } \\
\text { model }\end{array}$ & $\begin{array}{l}\text { Sensitivity } \\
\text { analysis }\end{array}$ & Optimization & Verification \\
\hline $\begin{array}{l}\text { Hydraulic } \\
\text { profile }\end{array}$ & Control points & circa 14 & Free & Fix & Fix & Fix \\
\hline \multirow{3}{*}{$\begin{array}{l}\text { Guide } \\
\text { blade }\end{array}$} & Control points & circa 11 & Free & Fix & Fix & Fix \\
\hline & Global rotation & 1 & Free & Free & Free & Free \\
\hline & Number of blades & 1 & Free & Fix & Fix & Fix \\
\hline \multirow{10}{*}{$\begin{array}{l}\text { Runner } \\
\text { blade }\end{array}$} & Inlet angle & 4 & Free & Free & Free & Fix \\
\hline & Outlet angle & 4 & Free & Free & Free & Fix \\
\hline & Profile length & 4 & Free & Free & Fix & Fix \\
\hline & $\begin{array}{l}\text { Maximum } \\
\text { blade thickness }\end{array}$ & 4 & Free & Fix & Fix & Fix \\
\hline & $\begin{array}{l}\text { Position of maximum } \\
\text { camber }\end{array}$ & 2 & Free & Free & Fix & Fix \\
\hline & $\begin{array}{l}\text { Maximum blade camber } \\
\text { ration }\end{array}$ & 2 & Free & Free & Fix & Fix \\
\hline & $\begin{array}{l}\text { The radius of the inlet } \\
\text { edge }\end{array}$ & 2 & Free & Fix & Fix & Fix \\
\hline & $\begin{array}{l}\text { Position of the blade } \\
\text { rotation points }\end{array}$ & 2 & Free & Fix & Fix & Fix \\
\hline & Global rotation & 1 & Free & Fix & Fix & Free \\
\hline & Number of blades & 1 & Free & Fix & Fix & Fix \\
\hline \multicolumn{3}{|c|}{ Number of free parameters } & 53 & 17 & 9 & 2 \\
\hline \multicolumn{3}{|c|}{ Number of simulation points } & - & 300 & circa 700 & circa 125 \\
\hline
\end{tabular}




\section{Acknowledgment}

This contribution was created during the project of Innovative Design of Compact Unit of Kaplan Micro-Turbine TH04010140, which is co-financed with the state support of the Technology Agency of the Czech Republic within the Epsilon Program.

\section{References}

[1] CAESES: manuals and blog, [online] [quoted 6.6.2019]. Available from z: www.caeses.com, 2019.

[2] ANSYS: manuals, [online] [quoted 6.6.2019]. Available from: www.ansys.com, 2019.

[3] DAKOTA: manual, [online] [quoted 6.6.2019]. Available from: https://dakota.sandia.gov/,2019.

[4] ŠTĚCH, S., KANTOR, M. (2014): Využití metod isogeometrické analýzy pro optimalizaci vodních turbín. [Use of isogeometric analysis methods to optimize water turbines] Proceedings. HYDROTURBO 2014, Bratislava.

[5] KANTOR, M. (2018): Numerické výpočty proudění v rotačních strojích [Numerical calculations of flow in rotary machines], Experimentálni a výpočtové metody v inženýrstuí, str. 16-24, Ústí nad Labem, ISBN 978-80-7561-122-2, 2018.

[6] GENTZSCH, W., KANTOR, M., YENIER, B. (2018). Kaplan turbine flow simulation using OpenFOAM in the Advania Cloud - An UberCloud Experiment [online] [quoted 28.5.2018].
Avaiable from: bttps://community.theubercloud.com/ team-198-kaplan-turbine-flow-simulationusing-openfoam-in-the-cloud/

[7] KANTOR, M. (2018). Strategie tvarové optimalizace oběžné lopatky Kaplanovy turbíny [Strategy of shape optimization of Kaplan turbine blade], Sborník konference Hydroturbo 2018, Bratislava, ISBN 978-80-227-4829-2.

[8] BENIGNI, H., MONTENARI, B., JABERG, H., SCHIFFER, J., GEHRER, A., GRUNDNER， F., DÖLTELMAYER, R (2016). Simulation of damages due to cavitation in non-rotating components in a Kaplan turbine, Conference: 19th Internationales Seminar Wasserkraftanlagen, At Laxenburg / Wien.

[9] SEMENOVA, A., CHIRKOV, D., LYUTOV, A., CHEMY, S., SKOROSPELOV, V., PYLEV, I. (2014). Multi-objective shape optimization of runner blade for Kaplan turbine, 27th LAHR Symposium on Hydraulic Macbinery and Systems (IAHR 2014).

[10] PETRU, M., MLYNEK, J., MARTINEC, T. (2018). Numerical Modelling for Optimization of Fibres Winding Process of Manufacturing Technology for the Non-Circular Aerospaces Frames. Manufacturing Technology, 18(1), 90-98. doi: $\quad$ 10.21062/ujep/59.2018/a/12132489/MT/18/1/90.

[11] KALINA, T., HELLER, P., CHVAL, Z., SEDLÁČEK, F., KŘÍŽEK, M., BARTOŇ, L. (2018). Numerical Simulation and Experimental Testing of Two-axle Chassis of Low-floor Trams. Manufacturing Technology, 18(2), 248-254. doi: $\quad 10.21062 /$ ujep/86.2018/a/12132489/MT/18/2/248. 